\title{
COMPARAÇÃO DOS EMENTÁRIOS DAS DISCIPLINAS DE NATA- ÇÃO NOS CURSOS DE LICENCIATURA E BACHARELADO EM EDUCAÇÃO FÍSICA NO BRASIL E SUAS CONSEQUÊNCIAS
}

\author{
Malvina Exquibel \\ Universidade do Estado De Santa Catarina, Florianópolis, Santa Catarina, Brasil. \\ Suzana Matheus Pereira \\ Universidade do Estado De Santa Catarina, Florianópolis, Santa Catarina, Brasil. \\ Caroline Ruschel \\ Universidade do Estado De Santa Catarina, Florianópolis, Santa Catarina, Brasil. \\ Gustavo Soares Pereira \\ Universidade do Estado De Santa Catarina, Florianópolis, Santa Catarina, Brasil.
}

\begin{abstract}
Resumo
Comparou-se as ementas e/ou conteúdos das disciplinas de Natação/Atividades Aquáticas pertencentes às fases de adaptação e ensino dos nados dos cursos de licenciatura e bacharel em Educação Física de 42 universidades públicas brasileiras que oferecem os dois cursos concomitantemente, para conhecer as diferenças e similitudes entre as duas modalidades da graduação. Verificou-se que $74 \%$ das universidades apresentaram conteúdos e créditos idênticos ou similares, inferindo que uma quantidade significativa de graduados em Educação Física nas instituições públicas no Brasil tem similares bases teóricas e subsídios curriculares necessários para intervir nos campos de trabalho da adaptação e ensino dos nados em qualquer âmbito, seja este formal ou não formal.

Palavras-chave: Natação. Curriculum. Licenciatura. Bacharelado.

\section{COMPARISON OF THE CONTENT OF SWIMMING PROGRAM OF PHYSICAL EDUCATION AND BACHELOR'S IN SPORTS SCIENCES DEGREES IN BRAZIL AND ITS CONSEQUENCES}

\begin{abstract}
The aim of the study was to compare the content of class programs on swimming/aquatic activities regarding the process of adaptation and teaching of the competitive strokes in Physical Education and Bachelor's in Sports Sciences Degrees of 42 public universities in Brazil that offered both of the degrees. The paper sought to understand the differences and similarities of both Degrees. It was found that $74 \%$ of the universities have identical or at least similar content and credits in both programs. It is possible to conclude that a significative portion of the students in both programs have similar theorical bases and curricular subsidies to intervene on the process of adaptation and teaching of competitive strokes, such in formal and informal fields.
\end{abstract}

Keywords: Swimming. Curriculum. Physical Education. Sports Sciences. 


\title{
COMPARACIÓN DE LOS CONTENIDOS DE LAS ASIGNATURAS DE NA- TACIÓN EN LOS CURSOS DE LICENCIATURA Y BACHILLERATO EN EDUCA- CIÓN FÍSICA EN BRASIL Y SUS CONSECUENCIAS
}

\begin{abstract}
Resumen
Se compararon los contenidos de las asignaturas de Natación/Actividades Acuáticas pertenecientes a las fases de adaptación e enseñanza de los nados de los cursos de Licenciatura y Bachiller en Educación Física de 42 universidades públicas brasileñas que ofrecen los dos cursos concomitantemente, para conocer las diferencias y similitudes entre las dos modalidades de la graduación. Se verificó que el $74 \%$ de las universidades presentaron contenidos y créditos idénticos o similares, infiriendo que una cantidad significativa de graduados en Educación Física en las instituciones públicas en Brasil tiene similares bases teóricas y subsidios curriculares necesarios para intervenir en los campos de trabajo de la adaptación y enseñanza de los nados en cualquier ámbito, ya sea formal o no formal.
\end{abstract}

Palabras clave: Natación. Plan de estudios. Licenciatura. Bachiller.

\section{Introdução}

As atividades aquáticas não são alheias à controversa temática sobre os campos de intervenção de bacharéis e licenciados em Educação Física (EF). Este debate entra em destaque quando se trata da adaptação ao meio líquido e do ensino dos nados, em que crianças e adultos usufruem de estratégias didático-pedagógicas para alcançar os objetivos básicos.

Com a criação do curso de Bacharelado, através da resolução $n^{\circ}$ 03/87 do Conselho Federal de Educação (CFE), e com a resolução 023/2000 do Conselho Federal de Educação Física (CONFEF), que dispõe sobre a fiscalização e orientação do exercício profissional e das pessoas jurídicas, os graduados licenciados em EF foram impedidos de trabalhar com a iniciação em atividades aquáticas fora do âmbito escolar, o que, na prática, inviabiliza essa atuação, já que são escassas as instituições escolares que oferecem este componente no seu quadro curricular.

Segundo o documento apresentado pelo CONFEF em 2015, "Intervenção profissional e formação superior em Educação Física: articulação necessária para a qualidade do exercício profissional", o campo de intervenção profissional do licenciado em EF são as "instituições de Ensino de Educação Básica" (CONFEF, 2015, p. 53). Os campos de intervenção do bacharel em EF são "academias, clubes, estúdios, clínicas, hospitais, condomínios, Instituições de Ensino Superior (IES), programas públicos e privados de saúde, de atividade física, de exercício físico, de esportes, incluindo dança e lutas, de lazer e de gestão esportiva" (CONFEF, 2015, p.73).

Essas especificidades da intervenção profissional dos graduados em EF estão justificadas, segundo o CONFEF, pelas dimensões de organização dos cursos de licenciatura e bacharelado em EF com o objetivo de conceder à sociedade o direito de ser atendida por profissionais qualificados (CONFEF, 2015).

As dimensões referidas são especificadas na resolução do Conselho Nacional de Educação, Câmara de Educação Superior (CNE/CES) no 07/2004 que institui as Diretrizes Curriculares Nacionais para os cursos de graduação em Educação Física, em nível superior de graduação plena. Nesse documento, elencam-se as dimensões e os conteúdos que devem ser inseridos nos cursos de graduação em EF, licenciatura e bacharelado, e as dimensões do conhecimento que devem abranger. Ele é o norteador para a construção dos projetos pedagógicos das 
IES, e lista os elementos que qualificarão o graduado em EF e determinarão suas competências e habilidades (BRASIL, 2004b).

No que tange às licenciaturas, a resolução do Conselho Nacional de Educação, Conselho pleno (CNE/CP) no 02/ 2015 define as Diretrizes Curriculares Nacionais para a formação inicial em nível superior dos cursos de licenciatura. Nesse documento, institui-se núcleos de estudo de formação geral e de aprofundamento que se constituem em conhecimentos e conteúdos que incluem, entre outros: conhecimentos pedagógicos; observação, análise, planejamento, desenvolvimento e avaliação de processos educativos e de experiências educacionais em instituições educativas; conhecimento multidimensional e interdisciplinar sobre o ser humano e práticas educativas, incluindo conhecimento de processos de desenvolvimento de crianças, adolescentes, jovens e adultos, nas dimensões física, cognitiva, afetiva, estética, cultural, lúdica, artística, ética e biopsicossocial; pesquisa e estudo dos conteúdos específicos e pedagógicos (BRASIL, 2015).

O CONFEF, na intenção de esclarecimento e sistematização do conjunto de conhecimentos para os cursos de EF, organizou dois quadros distintos com os campos "Dimensões do conhecimento", "áreas de conhecimento" e "conhecimentos necessários para a intervenção profissional" para o bacharelado e a licenciatura, elencando as disciplinas dos cursos e suas correspondências (CONFEF, 2015). No Quadro 1 visualizam-se as atividades aquáticas nas dimensões e áreas de conhecimentos, segundo classificação do CONFEF no seu documento "Intervenção profissional e formação superior em Educação Física", de 2015.

Quadro 1 - Estruturação de conhecimentos necessários para a intervenção profissional.

\begin{tabular}{|c|c|c|}
\hline \multicolumn{3}{|c|}{ LICENCIATURA } \\
\hline $\begin{array}{l}\text { Dimensões do conheci- } \\
\text { mento }\end{array}$ & $\begin{array}{l}\text { Áreas de conhecimen- } \\
\text { to }\end{array}$ & $\begin{array}{l}\text { Conhecimentos necessários } \\
\text { para a intervenção profissional }\end{array}$ \\
\hline $\begin{array}{l}\text { Técnico-Instrumental } \\
\text { Conhecimentos e proce- } \\
\text { dimentos específicos que } \\
\text { contribuem para a caracte- } \\
\text { rização da área e fornecem } \\
\text { suporte para a intervenção } \\
\text { profissional na educação } \\
\text { básica. }\end{array}$ & $\begin{array}{l}\text { Esportiva } \\
\text { Estudo do esporte e o } \\
\text { esporte como ferra- } \\
\text { menta de formação } \\
\text { integral. }\end{array}$ & $\begin{array}{l}\text { Metodologia do Ensino das } \\
\text { Atividades Aquáticas } \\
\text { As atividades no meio líquido } \\
\text { como parte da formação inte- } \\
\text { gral, processos de adaptação } \\
\text { ao meio líquido, procedimen- } \\
\text { tos pedagógicos para aprendi- } \\
\text { zagem da natação em ambien- } \\
\text { te escolar e nados utilitários. }\end{array}$ \\
\hline \multicolumn{3}{|c|}{ BACHARELADO } \\
\hline $\begin{array}{l}\text { Dimensões do conheci- } \\
\text { mento }\end{array}$ & $\begin{array}{c}\text { Áreas de conhecimen- } \\
\text { to }\end{array}$ & $\begin{array}{l}\text { Conhecimentos necessários } \\
\text { para a intervenção profissional }\end{array}$ \\
\hline $\begin{array}{l}\text { Técnico-Instrumental } \\
\text { Conhecimentos técnicos e } \\
\text { procedimentos específicos } \\
\text { da área e de áreas correla- } \\
\text { tas. }\end{array}$ & $\begin{array}{l}\text { Esportiva } \\
\text { Estudo do esporte, } \\
\text { modalidades esporti- } \\
\text { vas, formas de desen- } \\
\text { volvimento e de apli- } \\
\text { cação do esporte. }\end{array}$ & $\begin{array}{l}\text { Natação } \\
\text { Origem e evolução histórica, } \\
\text { desenvolvimento, aperfeiçoa- } \\
\text { mento dos estilos crawl, cos- } \\
\text { tas, peito e borboleta, princí- } \\
\text { pios técnicos e regulamentos, } \\
\text { planejamento e estruturação } \\
\text { de aulas, e competições de } \\
\text { natação. }\end{array}$ \\
\hline
\end{tabular}


A partir do exposto, observam-se dimensões e áreas de conhecimentos equivalentes e habilidades para a intervenção profissional que se assemelham nas primeiras fases do ensino das atividades aquáticas/natação (Adaptação, Ensino dos nados) e um distanciamento na fase do Treinamento/Competição.

Analisando como são construídas as grades curriculares das IES, a similitude na estruturação do conhecimento dos cursos de bacharelado e licenciatura proposta pelo CONFEF é colocada em pauta, mas também é relevante o que diz o parecer CNE/CES 58/2004 sobre as Diretrizes Curriculares Nacionais para os cursos de graduação em Educação Física, que ratifica a autonomia e flexibilidade que as IES detêm para elaborar os projetos pedagógicos e curriculares dos seus cursos.

Essa autonomia institucional pode favorecer a conciliação da realidade de um mercado de trabalho diversificado, cada vez mais competitivo e em expansão, com a formação de um profissional que alie os conhecimentos e instrumentos específicos da sua área a uma ampla e consistente visão da realidade humana, social, política e econômica do país. (BRASIL, 2004a, p. 7).

Ponderando esse cenário, relacionando-o com as atividades aquáticas e compreendendo que as primeiras fases do processo de ensino da natação serão desenvolvidas com os mesmos objetivos no contexto escolar ou não escolar, questiona-se a designação, segundo documentos do CONFEF, dessa área de intervenção fora do âmbito escolar, exclusiva para bacharéis.

Com o intuito de elucidar a questão da diferença na formação de licenciados e bacharéis para atuação no ensino da natação nas suas fases de adaptação e ensino dos nados, realizou-se o presente estudo, comparando as ementas e/ou conteúdos das disciplinas de Natação/Atividades Aquáticas dos cursos de licenciatura e bacharelado em Educação Física de universidades públicas brasileiras que oferecem os dois cursos concomitantemente, elencando e categorizando os conteúdos ministrados e pertencentes às referidas fases.

\section{O potencial de infraestruturas para a prática e ensino da natação no Brasil}

As atividades aquáticas são práticas elitizadas e de difícil acesso no Brasil e em vários outros países. Há poucas instituições educacionais com piscinas próprias, as públicas são escassas e as Instituições de Ensino Básico privadas que oferecem esta modalidade como atividade extracurricular, muitas vezes não utilizam uma infraestrutura própria. A alternativa para que a população que não tem acesso pratique atividades aquáticas são os clubes, as academias de ginástica e as academias ou escolas de natação, que são instituições privadas e que oferecem este serviço com custos relativamente elevados. A literatura é carente em estudos que mostrem a quantidade de escolas, academias ou clubes que trabalham com natação no Brasil, e a quantidade de alunos que estas instituições possuem.

Segundo pesquisa do IBGE (BRASIL, 2016), das 27 unidades federativas, 26 declararam possuir instalações esportivas de sua propriedade e, entre elas, só 11 unidades possuem piscina. $\mathrm{O}$ documento não se refere a piscinas sob a administração de gestões estaduais. $\mathrm{Na}$ mesma pesquisa, foi informada a existência de 3.971 escolas da rede pública municipal com instalações esportivas, das quais só 265 unidades possuem piscina. Isso revela a pequena parcela de alunos que usufruem de aulas de natação ou atividades aquáticas dentro do âmbito escolar público.

Como exposto no Atlas do Esporte, publicado em 2005 e apresentado na Figura 1, a quantidade de piscinas não residenciais levantadas foi de 12.160 , correspondente a $66,5 \%$ do somatório de municípios brasileiros (DA COSTA, 2005). 
Figura 1: Distribuição de instalações esportivas no Brasil, que inclui as piscinas não residenciais

Totais Brasil / Final numbers of sport facilities in Brazil

Instalaçóes esportivas - Brasil / Sport facilities - Brasil, 2003

Número de Municípios do País / Number of municipalities in the state -5.493

Número de Municipios Informantes / Number of respondent municipalities - 3.653

Base de informaçōes / Data base: Sistema CONFEF/CREF's e INDESP 2000

\begin{tabular}{|l|c|}
\hline Estádios / stadiums & 331 (12 informantes) \\
\hline Quadras / courts & 31.297 \\
\hline Piscinas não residenciais / non residentia/ swimming pools & 12.160 \\
\hline Pistas de atletismo / athletics tradss & 686 \\
\hline Ginásios / indoor gymnasiums & 5.381 \\
\hline Campos de futebol / soccer fields & 29.073 \\
\hline
\end{tabular}

Fonte: Atlas do Esporte, 2005.

Destaca-se o contraste dos dados entre as piscinas pertencentes ao âmbito escolar (276) e as piscinas não residenciais (12.160), o que infere ao raciocínio de que a maioria dos praticantes de natação realiza suas atividades fora da escola e que a oportunização da prática da natação no âmbito escolar é mínima. Do mesmo modo, pode-se supor que devido a isso, os profissionais dessa área atuam, principalmente, fora das escolas.

\section{O profissional de EF e o ensino dos nados}

O profissional de EF que atuará na adaptação e ensino dos nados deve ter seu perfil traçado por meio dos conhecimentos e experiências adquiridos na sua passagem pelo curso de graduação. Para compreender como esse perfil está sendo construído, deve-se, inicialmente, definir o conteúdo que será tratado.

Fernandes e Lobo da Costa (2006, p. 6) conceituam a natação como:

[...] um conjunto de habilidades motoras que proporcionem o deslocamento autônomo, independente, seguro e prazeroso no meio líquido, sendo a oportunidade de vivenciar experiências corporais aquáticas e de perceber que a água é mais que uma superfície de apoio e uma dimensão, é um espaço para emoções, aprendizados e relacionamentos com o outro, consigo e com a natureza. Nesse sentido, o processo que leva a essa experiência e a esse aprendizado é chamado aqui de ensinoaprendizagem da natação, no qual os quatro estilos da natação competitiva são um dos conteúdos a serem desenvolvidos e não as metas do processo.

Como citam vários autores, esse processo de ensino-aprendizagem está desmembrado em três fases: Iniciação/Adaptação ao meio líquido; Ensino dos nados/Aperfeiçoamento; e Treinamento/Competição. Cada fase tem suas particularidades, mas existe uma interdependência destes componentes com a progressão dos elementos flutuação, respiração e propulsão (CATTEAU e GAROFF, 1990; LIMA, 1999; KRUG e MAGRI, 2012).

Segundo os autores, certos elementos se caracterizam em cada uma dessas fases da seguinte forma:

- A fase de Iniciação/Adaptação ao meio líquido se caracteriza pelos elementos: primeiros contatos com a água, respiração, flutuação, deslizamentos, saltos e noções de propulsão com o objetivo da familiarização e domínio do meio;

- A fase de Ensino dos nados/Aperfeiçoamento se caracteriza pela aprendizagem das técnicas de nado de cada estilo seguindo uma sequência pedagógica que envolve 
os elementos de posição do corpo, pernada, braçada, respiração, coordenação, saídas e viradas. Nessa fase, também podem ser incluídos elementos como nados utilitários, outras habilidades aquáticas, salvamento e primeiros socorros;

- A fase de Treinamento/Competição inicia depois da aquisição das técnicas de nado e depende das condições fisiológicas, físicas e psicológicas do nadador além da motivação. Essa fase se caracteriza pelo aprimoramento técnico dos nados, saídas e viradas e da aptidão física.

As duas primeiras fases aqui descritas (Adaptação e Ensino dos nados) têm sua importância exaltada enquanto conteúdos utilitários que contribuem para a sobrevivência do ser humano no meio aquático, o que determina seu valor.

Com o exposto, define-se como fases pertinentes a este estudo a adaptação e ensino dos nados, entendendo que a fase de treinamento está relacionada com a aptidão física ou com a competição. Esses conhecimentos e habilidades são exclusivos dos cursos de bacharelado em EF e não serão comparados neste estudo, dado que os cursos de licenciatura não apresentam os mesmos conteúdos.

Um profissional capacitado para atuar nessas duas primeiras fases precisa conhecer amplamente as dimensões didático-pedagógicas e procedimentais, os conhecimento de processos de desenvolvimento do ser humano nas dimensões física, cognitiva, afetiva, estética, cultural, lúdica, artística, ética e biopsicossocial, tanto para trabalhar com crianças como com outras populações. Estas dimensões são destaque na formação do licenciado em EF, o que o torna um profissional preparado para atuar nos processos de iniciação e aprendizagem da natação.

\section{A conjuntura da formação e dos campos de trabalho para a licenciatura e bacharelado em EF}

A fragmentação da formação profissional, através da resolução CFE 03/87 continua gerando grandes discussões sobre a formação e a intervenção dos profissionais graduados em EF. Esses dilemas se transferem também às universidades que deambulam perdidas tentando encontrar a melhor forma de se adequarem às mudanças, mesmo depois de anos de instituídas as leis que regulamentam tal fragmentação. Muitos autores mencionam as dificuldades das IES em definir as concepções, objetivos e perfis profissionais dos cursos de licenciatura e bacharelado em Educação Física. Segundo Nozaki (2004), isso ocorre em parte pela falta de clareza nas resoluções e pela dificuldade de vislumbrar uma formação diferente para um curso que desde sua concepção se utiliza da docência como eixo central de sua intervenção profissional.

Mendes e Prudente (2011) se deparam com problemas relacionados às licenciaturas e bacharelados, comprovando que suas matrizes curriculares são praticamente idênticas (não diferenciando conteúdos) e afirmando a falta de clareza na diferenciação das formações e dos possíveis campos de atuação.

Como Cruz expõe (2011, p. 41, grifo do autor):

Se analisarmos os currículos, veremos disciplinas iguais, ou currículos sendo "regulados" para diferenciar a formação entre licenciatura e bacharelado a partir da carga horária ou da mudança de nome da disciplina. Os conteúdos sobre os quais ambas as formações tratam são os mesmos, o que vai mudar é a intencionalidade pedagógica. A definição para os campos de atuação entre formais e não formais desconsidera a docência como a base em qualquer local de intervenção profissional. 
O parecer CNE/CES 58/2004, tentando esclarecer essas e outras discussões sobre os cursos de EF, apresenta os princípios norteadores das Diretrizes Curriculares para os cursos de graduação em EF que foram instituídas posteriormente pela resolução CNE/CES 07/2004. Em nenhum destes documentos se bifurcam os objetos de estudo e de aplicação para bacharelados e licenciaturas, pelo contrário, nomeia-se coletivamente como graduados em EF tanto bacharéis quanto licenciados. Resumidamente, na resolução CNE/CES 07/2004, em nenhum momento aparece a palavra bacharel ou bacharelado. Com relação à licenciatura, chama-se plena, e em suas orientações específicas contempla a qualificação para a docência. Vale esclarecer que o CONFEF integrou a comissão de especialistas que analisou e propôs estas Diretrizes Curriculares Nacionais (BRASIL, 2004a, 2004b).

Estas discussões se estendem aos campos de trabalho de licenciados e bacharéis, com diversas opiniões posicionadas em um ou outro extremo. As interpretações do CONFEF levam à delimitação dos campos de intervenção e à fiscalização de entidades e profissionais, autorizando apenas os bacharéis em EF a atuar na adaptação ao meio líquido e ensino dos nados em academias e clubes, deixando de fora profissionais igualmente capacitados para intervir nessa área e, por vezes, com a formação mais aprofundada em questões didáticopedagógicas e de desenvolvimento do ser humano nas dimensões física, cognitiva, afetiva, cultural, lúdica, e biopsicossocial, como os licenciados (BRASIL, 2015). Enquanto isso, a realidade traz demandas concretas: as escolas, os clubes e academias precisam de profissionais competentes, que atendam às necessidades do seu público, que pouco conhece sobre esta polêmica na formação de profissionais em Educação Física.

\section{Metodologia}

Considerando o objetivo analítico comparativo deste estudo, foi desenvolvida uma pesquisa exploratória documental de natureza qualitativa, visto que "a pesquisa documental vale-se de materiais que não receberam tratamento analítico ou que ainda podem ser reelaborados de acordo com o objetivo da pesquisa" (GIL, 2008, p. 51).

Os documentos que incluem os dados necessários para este estudo são as ementas ou os conteúdos ministrados nos cursos de EF, nas disciplinas de Natação/Atividades Aquáticas. Conhecendo a Lei $\mathrm{n}^{\mathrm{o}} 13.168$, de 6 de outubro de 2015, que altera a redação do $\S 1^{\circ}$ do art. 47 da Lei n ${ }^{\circ}$ 9.394/96 (Lei de Diretrizes e Bases da Educação Nacional) e determina a obrigatoriedade de publicação em página específica na internet, no sítio eletrônico oficial da IES dos programas dos cursos, componentes curriculares, sua duração, entre outros itens, optou-se por realizar uma pesquisa destes documentos na internet.

Com a finalidade de comparar os dados referentes aos cursos de bacharelados e licenciaturas, fez-se necessário investigar quais as IES que oferecem os dois cursos concomitantemente. Esta pesquisa realizou-se nas bases de dados do Ministério de Educação, no cadastro no e-MEC de Instituições e Cursos de Educação Superior (http://emec.mec.gov.br/). Esta base de dados é oficial e apresenta informações sobre as IES e cursos de graduação do Sistema Federal de Ensino.

Os relatórios obtidos pelo site e-MEC apresentaram 1663 cursos de EF com bacharelados e licenciaturas nas modalidades presenciais e a distância em atividade no Brasil, em 746 IES. A busca pelos documentos necessários para o levantamento das informações referentes a este estudo demonstrou que, na maior parte das vezes, as instituições não cumprem a Lei $\mathrm{n}^{\circ}$ 13.168, ou seja, nem sempre os documentos estão disponíveis nos sites oficiais, exigindo, portanto, buscas pormenorizadas e minuciosas por diversos locais dentro do site, a fim de obter dados como ementas, carga horária das disciplinas e obrigatoriedade. Sendo assim, optou-se por analisar exclusivamente as universidades públicas que oferecem o curso de Educa- 
ção Física nas modalidades bacharelado e licenciatura concomitantemente contemplando todo o território nacional.

\section{Análise de dados}

Foi feita a análise qualitativa dos documentos coletados, que foram processados analiticamente e transformados em dados compreensíveis, criteriosos e confiáveis (GIBBS, 2009). Analisou-se as ementas e conteúdos das disciplinas de Natação/Atividades Aquáticas das licenciaturas e bacharelados, identificando e categorizando os elementos pertencentes às diferentes fases do ensino da natação referentes a: Iniciação/Adaptação ao meio líquido; Ensino dos nados/Aperfeiçoamento; e Treinamento/Competição (CATTEAU e GAROFF, 1990; LIMA, 1999; KRUGe MAGRI, 2012). Analisou-se também, a obrigatoriedade de cursar a disciplina e a quantidade de créditos a serem cursados.

Como conteúdos referentes à Iniciação/Adaptação identificaram-se os seguintes termos: iniciação à natação, adaptação ao meio líquido, ambientação, primeiros contatos, habilidades básicas.

$\mathrm{Na}$ fase Ensino dos nados identificou-se: metodologia do ensino dos nados, planejamento, técnica dos diferentes estilos, ensino e aprendizagem da natação, aprendizagem dos estilos oficiais, princípios/processos didático-pedagógicos, estratégias de ensinoaprendizagem, procedimentos pedagógicos, aperfeiçoamento, exercícios educativos e corretivos, iniciação dos quatro estilos, sequência pedagógica, detecção e correção de erros, ensino das habilidades aquáticas, programas de aprendizagem e aperfeiçoamento, aspectos pedagógicos e metodológicos.

$\mathrm{Na}$ fase de Treino/Treinamento/Competição identificou-se: regras, treinamento, natação competitiva, periodização, alto desempenho, performance, atleta de natação, arbitragem, organização de competições.

Com a finalidade de compreender se um profissional de EF (bacharel ou licenciado) teria subsídios teóricos e práticos para atuar nas duas primeiras fases do ensino da natação, deu-se ênfase nos conteúdos relacionados à Iniciação/Adaptação e Ensino dos nados.

Uma vez categorizados os documentos e aferidos créditos e obrigatoriedade de cada disciplina, iniciou-se a análise comparativa. Nesse processo sistematizado, comparou-se primeiramente a similaridade de conteúdos e ementas das fases de Adaptação e Ensino dos nados, posteriormente comparou-se sua obrigatoriedade e a quantidade de créditos/horas-aula pertencentes a cada disciplina.

\section{Resultados e discussão}

O levantamento inicial totalizou 55 universidades com cursos de licenciatura e bacharelado em EF concomitantes. Foi feita uma busca on-line minuciosa para obter documentos que incluíssem créditos, ementas e/ou conteúdos das disciplinas dos cursos selecionados. Apenas 16 instituições apresentaram seus Projetos Pedagógicos nos sites oficiais, o que dificultou as buscas. Nas outras situações, foi necessária a procura de tabelas de horários das disciplinas, carga horária, créditos e ementários para chegar às informações necessárias.

Das 55 universidades selecionadas, 13 não apresentaram ementas nem conteúdos online, obtendo-se uma amostra final de 42 universidades analisadas. Estas universidades situam-se em todo o território nacional, sendo $14 \operatorname{IES}(33,33 \%)$ da região sul, 12 IES $(28,57 \%)$ da região sudeste, 10 IES $(23,81 \%)$ da região nordeste, quatro IES $(9,52 \%)$ da região centrooeste e dois IES $(4,76 \%)$ da região norte.

Das 42 universidades pesquisadas, 48\% (20 universidades) apresentaram conteúdos e créditos idênticos e 26\% (11 universidades) apresentaram conteúdos similares. As instituições 
que apresentaram conteúdos diferentes nas disciplinas de atividades aquáticas, distinguindo entre licenciatura e bacharelado, representaram 26\% (11 universidades). A Figura 2 representa os dados coletados e sua categorização.

Figura 2: Comparação de conteúdos relacionados à Iniciação/Adaptação e Ensino dos nados entre licenciaturas e bacharelados de uma mesma universidade

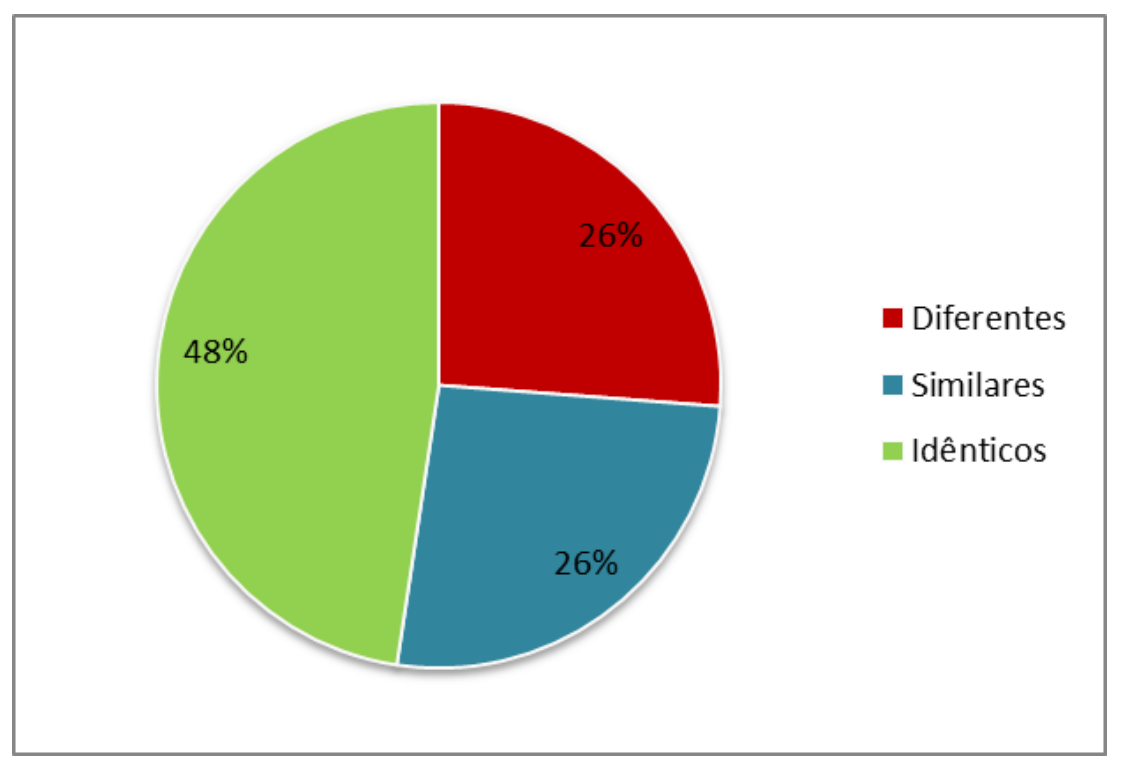

Consideraram-se como conteúdos "idênticos" os pertencentes aos bacharelados e licenciaturas da mesma IES, que apresentassem conteúdos/ementas, créditos e obrigatoriedade rigorosamente iguais. Constatou-se também, em algumas IES, o espelho de dados até no código da disciplina.

Como exemplo, transcrevem-se os dados de uma universidade nos Quadros 2 e 3:

Quadro 2 - Exemplo de disciplinas idênticas (bacharelado)

\begin{tabular}{|c|c|c|c|}
\hline Disciplina & $\begin{array}{l}\text { Tipo de } \\
\text { Disciplina }\end{array}$ & Carga Horária (h/a) & Ementa / Objetivo \\
\hline D000671 ATIVIDADES AQUÁTICAS & Obrigatória & 68 & $\begin{array}{l}\text { Ementa: Introdução ao ensino Natação. Aspectos metodológicos } \\
\text { do ensino da Natação. Adaptação ao meio líquido. Componentes } \\
\text { básicos do ensino da Natação. Atividades aquáticas recreativas e } \\
\text { técnicas do ensino dos estilos olímpicos: crawl e costas. Objetivo } \\
\text { geral: a) Propiciar aos alunos o conhecimento teórico e prático de } \\
\text { atividades em meio líquido, através de experiências didático- } \\
\text { pedagógicas na intenção de conhecer suas origens, relações e } \\
\text { contradições, de forma a praticá-lo na sua amplitude no contexto } \\
\text { educacional e profissional; e b) Articular a ligação entre teoria e } \\
\text { prática através das práticas pedagógicas como componente } \\
\text { curricular. }\end{array}$ \\
\hline
\end{tabular}


Quadro 3 - Exemplo de disciplinas idênticas (licenciatura)

\begin{tabular}{|l|l|l|l|}
\hline Disciplina & $\begin{array}{l}\text { Tipo de } \\
\text { Disciplina }\end{array}$ & Carga Horária (h/a) & $\begin{array}{l}\text { Ementa / Objetivo } \\
\text { D000671 ATIVIDADES AQUÁTICAS }\end{array}$ \\
\hline Obrigatória & 68 & $\begin{array}{l}\text { Ementa: Introdução ao ensino Natação. Aspectos metodológicos } \\
\text { do ensino da Natação. Adaptação ao meio líquido. Componentes } \\
\text { básicos do ensino da Natação. Atividades aquáticas recreativas e } \\
\text { técnicas do ensino dos estilos olímpicos: crawl e costas. Objetivo } \\
\text { geral: a) Propiciar aos alunos o conhecimento teórico e prático de } \\
\text { atividades em meio líquido, através de experiências didático- } \\
\text { pedagógicas na intenção de conhecer suas origens, relações e } \\
\text { contradições, de forma a praticá-lo na sua amplitude no contexto } \\
\text { educacional e profissional; e b) Articular a ligação entre teoria e } \\
\text { prática através das práticas pedagógicas como componente } \\
\text { curricular. }\end{array}$ \\
\hline
\end{tabular}

Categorizaram-se como conteúdos "similares" os pertencentes aos bacharelados e licenciaturas da mesma IES que apresentassem créditos e obrigatoriedade idênticos ou próximos nos elementos constitutivos das suas ementas e conteúdos. Esses dados não estão espelhados literalmente, mas os conteúdos trabalhados nas duas primeiras fases do ensino da natação são os mesmos.

Exemplo disso são as ementas desta instituição apresentadas nos Quadros 4 e 5:

Quadro 4 - Exemplo de disciplinas similares (bacharelado)

\begin{tabular}{|l|l|c|l|}
\hline Disciplina & $\begin{array}{l}\text { Tipo de } \\
\text { Disciplina }\end{array}$ & Carga Horária (h/a) & \multicolumn{1}{|c|}{ Ementa / Objetivo } \\
\hline EDF0013- ATIVIDADES AQUÁTICAS & Obrigatória & 60 & $\begin{array}{l}\text { ESTUDO DOS DESPORTOS INDIVIDUAIS AQUÁTICAS COMO } \\
\text { FENÔMENO SÓCIO-HISTÓRICO-POLÍTICO-CULTURAL. PRINCÍPIOS E } \\
\text { MODALIDADES DOS DESPORTOS AQUÁTICOS, ASPECTOS TÉCNICOS } \\
\text { E METODOLÓGICOS NAS SUAS INTERVENÇÕES NO SISTEMA } \\
\text { DESPORTIVOS, DO LAZER E DA SAÚDE. }\end{array}$ \\
\hline
\end{tabular}

Quadro 5 - Exemplo de disciplinas similares (licenciatura)

\begin{tabular}{|c|c|c|c|}
\hline Disciplina & $\begin{array}{l}\text { Tipo de } \\
\text { Disciplina }\end{array}$ & $\begin{array}{l}\text { Carga Horária } \\
\text { (h/a) }\end{array}$ & Ementa / Objetivo \\
\hline $\begin{array}{l}\text { EDF0058- METODOLOGIA DO } \\
\text { ENSINO DA NATAÇÃOO }\end{array}$ & Obrigatória & 60 & $\begin{array}{l}\text { ESTUDO DA NATAÇÃO COMO FENÔMENO SÓCIO-HISTÓRICO- } \\
\text { POLÍTICO-CULTURAL. PRINCÍPIOS E MODALIDADES DA NATAÇÃO, } \\
\text { ASPECTOS TÉCNICOS E METODOLÓGICOS DO ENSINO DA } \\
\text { NATAÇÃO NA ESCOLA NA PERSPECTIVA DO DESPORTO, DO LAZER E } \\
\text { DA SAÚDE. CONHECER OS NOÇÕES DE HIGIENE E SEGURANÇA DOS } \\
\text { ESPAÇOS AQUÁTICOS. APRENDIZAGEM INICIAL DOS QUATROS } \\
\text { NADOS }\end{array}$ \\
\hline
\end{tabular}

Das universidades analisadas, 26\% (11 universidades) apresentaram conteúdos "diferentes" entre bacharelado e licenciatura, com desigualdades na obrigatoriedade, nos créditos e nos conteúdos/ementas referentes às fases de adaptação e ensino dos nados. Ademais, apontam-se dimensões pedagógicas próprias para o ensino na educação básica e dimensões técnicas nos bacharelados. Destaca-se o contraste entre os conteúdos das disciplinas, seus créditos e sua obrigatoriedade, muitas vezes deixando explícito o campo de atuação de cada profissional. Exemplificando, pode-se citar universidades com mais de uma disciplina obrigatória na área das atividades aquáticas no bacharelado e disciplinas optativas na mesma área para a licenciatura e também a especificação "natação em ambientes educacionais" para a licenciatura e "treinamento/análise de desempenho/organização de competições" para o bacharelado. Ressalta-se ainda como diferença, uma instituição que nomeia as disciplinas do bacharelado e 
a licenciatura como "Metodologia do treino da natação" e "Pedagogia do ensino da natação" respectivamente.

Pode-se destacar alguns exemplos controversos quando da comparação dos conteúdos dos dois cursos: conteúdos como "educação básica", "educação física escolar" e "cotidiano escolar" em ementas de bacharelado; a abertura do campo de atuação para o licenciado e o bacharelado tanto no âmbito escolar como não escolar; conteúdos como "treino de natação para escolas, academias entre outras instituições que fazem uso da natação como programa de manutenção da saúde" para ambos os cursos; considerar a disciplina de atividades aquáticas obrigatória apenas para licenciatura. Sobressaem na análise que ementas e conteúdos não estão claramente bifurcados e concordantes com os perfis sugeridos pelo CONFEF para os diferentes campos de atuação.

Como pode ser observado na Figura 2, a maioria das universidades analisadas (74\%) possui disciplinas com conteúdos idênticos ou similares relacionados à Iniciação/Adaptação e Ensino dos nados, sendo equivalentes a quantidade de créditos nas disciplinas obrigatórias.

Mesmo evidenciando esses dados nas informações divulgadas pela maioria das instituições, definem-se os perfis dos graduados diferenciando bacharéis de licenciados. Pode-se constatar que se identificam certas incoerências nas quais as características de bacharéis e licenciados se misturam ou permutam, segundo analisou-se nos seus currículos. No entanto, essas instituições têm autonomia para elaborarem seus projetos pedagógicos, como colocado no parecer CNE/CES 58/2004.

A LDB possibilita às Instituições demonstrarem competência para elaboração do projeto pedagógico e curricular de seus cursos, com ampla liberdade para interagir com as peculiaridades regionais, com o contexto institucional, com as demandas do mercado de trabalho e com as características, interesses e necessidades da comunidade. (BRASIL, 2004a, p. 7)

Essas instituições determinaram formar profissionais com capacidades e habilidades equivalentes em muitas áreas de conhecimentos, o que pode significar campos de atuação idênticos. Ora, segundo o expresso nas Diretrizes Curriculares Nacionais, é possível desenvolver as mesmas dimensões de conhecimentos em ambos os cursos. O conflito se revela quando entidades que se dizem detentoras da decisão de definir os campos de intervenção dos profissionais de EF agem contrariamente, ao impedir que parte desses profissionais disputem a mesma área de atuação.

Como revela Fernandes Júnior (2011) em seu artigo publicado no site Jus.com.br, "inexiste no ordenamento jurídico brasileiro qualquer lei que proíba o licenciado em Educação Física de atuar nas academias e clubes". Considera-se também pertinente lembrar que atos administrativos e normativos são hierarquicamente inferiores à lei, e que a única lei que regulamenta o exercício da profissão do profissional da Educação Física é a Lei no 9.696/98, que não estabelece qualquer restrição ao licenciado em Educação Física.

Ponderando o conteúdo exposto, é inevitável indagar se licenciados e bacharéis estão igualmente preparados para atuar na iniciação esportiva no Brasil. Este questionamento, inicialmente focado numa modalidade, poderá ser transferido a outras, ressaltando os inconvenientes das bases legais da nossa profissão e a incongruência com as necessidades que a sociedade impõe.

\section{Considerações finais}

O objetivo do presente estudo foi comparar qualitativamente ementas e/ou conteúdos das disciplinas de Natação/Atividades Aquáticas dos cursos de Licenciatura e Bacharelado em 
Educação Física de universidades públicas brasileiras que oferecem os dois cursos concomitantemente. Nenhuma universidade privada foi analisada.

Diante das constatações inferidas neste estudo, é possível afirmar que uma quantidade significativa de graduados em EF nas instituições públicas no Brasil, tanto nos cursos de licenciatura como de bacharelado, possuem similares bases teóricas e subsídios curriculares necessários para intervir nos campos de trabalho da adaptação e ensino dos nados em qualquer âmbito, seja escolar ou não escolar.

A análise qualitativa dos documentos apresentou similitudes entre os conteúdos ministrados nas disciplinas relacionadas às atividades aquáticas na maioria das universidades públicas com cursos de bacharelado e licenciatura em EF.

Pode-se sugerir que o profissional licenciado em EF tem um perfil que o faz tão ou mais capacitado que o bacharel para intervir na área de Adaptação ao meio líquido e Ensino dos nados.

Tratando-se de uma temática que envolve discussões político-educativas e mercadológicas, considera-se que as entidades de ensino superior devem se posicionar junto às entidades controladoras (Sistema CONFEF/CREFS) quanto à delimitação dos contextos de intervenção de bacharéis e licenciados, redefinindo-os por meio de estudos e análises sobre o público-alvo das práticas corporais e do mercado atual. Caso contrário, permanecerá o contexto atual de simplesmente aplicar sem critérios o que é imposto com o intuito de fiscalizar e aplicar multas num sistema impregnado de controvérsias e conflitos.

Salientando que este estudo se baseou na análise de conteúdos das atividades aquáticas nas universidades públicas, encorajam-se outros profissionais a pesquisar as mesmas variáveis dentro de outras disciplinas e outras instituições de ensino superior. Nesta direção, indaga-se se a iniciação esportiva não deveria ser campo de intervenção tanto de bacharéis como de licenciados.

\section{Referências}

BRASIL. Conselho Nacional de Educação - Câmara de Educação Superior. Parecer CNE/CES 58/2004, de 18 de Fevereiro de 2004. Diretrizes Curriculares Nacionais para os cursos de graduação em Educação Física. Diário Oficial da União, Brasília, 19 de março de 2004. Disponível em: http://portal.mec.gov.br/cne/arquivos/pdf/2007/pces058_04.pdf. Acesso em: 25 set. 2017.

BRASIL. Conselho Nacional de Educação - Conselho Pleno. Resolução CNE/CP n ${ }^{\circ}$, de 18 de fevereiro de 2002. Institui Diretrizes Curriculares Nacionais para a Formação de Professores da Educação Básica, em nível superior, curso de licenciatura, de graduação plena. Diário Oficial da União, Brasília, 19 de fev. de 2002. Disponível em:http://portal.mec.gov.br/seesp/arquivos/pdf/res1_2.pdf. Acesso em: 25 set. 2017.

BRASIL. Conselho Nacional de Educação - Conselho Pleno. Resolução CNE/CP n ${ }^{\circ}$ 2,de 19 de fevereiro de 2002. Institui a duração e a carga horária dos cursos de licenciatura, de graduação plena, de formação de professores da Educação Básica em nível superior. Diário Oficial da União, Brasília, 4 de março de 2002. Seção 1, p. 9. Disponível em: http://portal.mec.gov.br/cne/arquivos/pdf/CP022002.pdf. Acesso em: 25 set. 2017.

BRASIL. Conselho Nacional de Educação - Conselho Pleno. Resolução CNE/CP no 7, de 31 de março de 2004. Institui as Diretrizes Curriculares Nacionais para os cursos de graduação em Educação Física, em nível superior de graduação plena. Diário Oficial da União, Brasília, 
5 de abril de 2004, Seção 1, p. 18. Disponível em: http://portal.mec.gov.br/cne/arquivos/pdf/ces0704edfisica.pdf. Acesso em: 25 set. 2017.

BRASIL. Conselho Federal de Educação. Resolução n 03/87, de 16 de junho de 1987. Fixa os mínimos de conteúdo e duração a serem observados nos cursos de graduação em Educação Física (Bacharelado e/ou Licenciatura Plena). Diário Oficial da União, Brasília, 10 de set. de 1987. Disponível em: http://crefrs.org.br/legislacao/pdf/resol_cfe_3_1987.pdf. Acesso em: 25 set. 2017.

BRASIL. IBGE - Instituto Brasileiro de Geografia e Estatística. Pesquisa de Informações Básicas Estaduais. Pesquisa de Informações Básicas Municipais. Perfil dos estados e dos municípios brasileiros: esporte: 2016 / IBGE, Coordenação de População e Indicadores Sociais. Rio de Janeiro: IBGE, 2017. Disponível em:https://www.ibge.gov.br/estatisticasnovoportal/sociais/protecao-social/2421-np-pesquisa-de-informacoes-basicas-

estaduais/16770-pesquisa-de-informacoes-basicasestaduais.html?edicao=10693\&t=downloads. Acesso em: 25 set. 2017.

BRASIL. Lei $\mathbf{n}^{\mathbf{0}} \mathbf{1 3 . 1 6 8}$, de 6 de outubro de 2015. Altera a redação do $\S 1$ to do art. 47 da Lei no 9.394, de 20 de dezembro de 1996 - Lei de Diretrizes e Bases da Educação Nacional. Diário Oficial da União, Brasília, 7 de outubro de 2015. Disponível em: https://www.planalto.gov.br/ccivil_03/_Ato2015-2018/2015/Lei/L13168.htm\#art1. Acesso em: 20 out. 2017.

CATTEAU, R.; GAROFF, G. O ensino da natação. São Paulo: Manole, 1990.

CONSELHO FEDERAL DE EDUCAÇÃO FÍSICA (CONFEF). Resolução CONFEF no 023/2000. Disponível em: http://www.confef.org.br/confef/resolucoes/23. Acesso em: 21 out. 2017

CONSELHO FEDERAL DE EDUCAÇÃO FÍSICA (CONFEF). Sistema CONFEF/CREFs Conselhos Federal e Regionais de Educação Física. Intervenção profissional e formação superior em educação física: articulação necessária para a qualidade do exercício profissional, 2015. Disponível em: https://www.google.com.br/url?sa=t\&rct=j\&q=\&esrc=s\&source=web\&cd=1\&cad=rja\&uact= 8\&ved=0ahUKEwiX367B7fLWAhVBIpAKHQxXDuAQFggnMAA\&url=http\%3A\%2F\%2F www.listasconfef.org.br\%2Farquivos\%2FINTERVENCAO_DOCUMENTO_FINAL.pdf\&us g=AOvVaw2rl5goM2YmpZIDS31RYX76. Acesso em: 25 set. 2017.

CORREA, C. R. F.; MASSAUD, M. G. Escola de natação. Rio de Janeiro: Sprint, 1999.

CRUZ, A. S. O embate de projetos na formação de professores de educação física: além da dualidade licenciatura-bacharelado. Motrivivência, Florianópolis, v. 23, n. 36, p. 26-44, 2011.

DACOSTA, L. P. Atlas do esporte no Brasil: atlas do esporte, educação física e atividades físicas de saúde e lazer no Brasil (Atlas of sports in Brazil: atlas of sports, of physical education and of physical activities for health and for leisure in Brazil). Rio de Janeiro: Shape, 2005 .

FERNANDES JÚNIOR, E. L. O direito do licenciado em educação física ao livre exercício da profissão em quaisquer das áreas de atuação profissional. Revista Jus Navigandi, Teresi- 
na, ano 16, n. 2852,23 abr. 2011. Disponível em: https://jus.com.br/artigos/18948. Acesso em: 21 out. 2017.

FERNANDES, J. R. P.; LOBO DA COSTA, P. H. Pedagogia da natação: um mergulho para além dos quatro estilos. Revista Brasileira de Educação Física e Esporte, v. 20, n. 1, p. 514, 2006.

GIBBS, G. Análise de dados qualitativos: coleção pesquisa qualitativa. Porto Alegre: Artmed, 2009.

GIL, A. C. Métodos e técnicas de pesquisa social. 6ª ed. São Paulo: Atlas, 2008.

KRUG, D. F.; MAGRI, P. E. F. Natação: aprendendo a ensinar. São Paulo: All Print, 2012

LIMA, W. U. Ensinando natação. São Paulo: Phorte Editora, 1999.

MENDES, C. L.; PRUDENTE, P. L. G. Licenciatura x bacharelado: o currículo da educação física como uma arena de luta. Revista Impulso, v. 21, n 51, p. 97-108, 2011.

NOZAKI, H. T. Educação física e reordenamento no mundo do trabalho: mediações da regulamentação da profissão. 2004. 399 f. Tese (Doutorado em Educação). Programa de PósGraduação em Educação, Universidade Federal Fluminense, Niterói, 2004.

Recebido em: 27/08/2018

Revisado em: 27/03/2019

Aprovado em: 27/03/2019

Endereço para correspondência:

malviros@hotmail.com

Malvina Exquibel

Universidade do Estado de Santa Catarina

Av. Madre Benvenuta, 2007

Itacorubi,

88.035-901 - Florianópolis / SC, Brasil. 